\title{
Audiencias Activas en el uso del Facebook y obtención de gratificaciones
}

\section{Resumen}

El ensayo se centra en la incorporación de Facebook en los procesos de interacción de los usuarios, un espacio virtual en donde lo privado se hace público. Supone una transformación radical de la función del público. Se intenta dar al estudio un carácter estructuralista, fundado en la teoría de Usos y Gratificaciones que se pueden lograr con los contenidos mediáticos. Desde la perspectiva del comunicador, se analizan los procesos de significación de los discursos; además, se presentan las características del discurso virtual en un caso de una persona con mil 567 "amigos" en su cuenta de Facebook, quien después de escribir una pregunta obtiene, a los pocos minutos, 123 "me gusta" y 92 comentarios que expresan sentimientos y opiniones a favor y en contra.

Palabras clave: Facebook, teoría de Usos y Gratificaciones, discurso virtual, significación de los discursos, sentimientos y opiniones.

\section{Active audiences in the use of Facebook and obtaining of gratifications}

\section{Abstract}

The essay is based on the incorporation of Facebook in the interaction processes of users, virtual space where private matters become public. A radical transformation of the function of the audience is assumed. The nature of this study is structuralist based on the Uses and Gratifications theory which can be achieved with media contents. From the communicator's point of view, discourse significance is analyzed. Also the characteristics of virtual discourse is
Carmen Vidaurre Güiza

Recibido el 2 de diciembre de 2015

Aceptado el 20 de diciembre de 2015 
presented in the case of a person with 1567 "friends" on his Facebook account, who soon after writing a question obtains 123 "Likes" and 92 comments expressing feelings and opinions in favor and against.

Keywords: Facebook, Uses and Gratifications theory, virtual discourse, significance of discourse, feelings and opinions.

Como parte de la formación que se brinda en la carrera de Ciencias de la Comunicación es inherente, en la actualidad, estudiar, analizar y tratar de comprender cómo las nuevas tecnologías han irrumpido en los procesos de interacción entre usuarios que acceden al innovador sistema denominado Internet; y que incluso hacen "propio" espacios, como por ejemplo, el popularmente conocido Facebook.

Todos contamos con Facebook, o al menos se da por sentado que así es. Un espacio virtual en donde lo privado se convierte en público. Un binomio muy particular equiparable a los lados de una moneda. Un espacio en donde convergen las personas agrupadas por este usuario muy particular, que ya entre las décadas del setenta y ochenta Marshall McLuhan y Alvín Toffler, denominaron como Prosumer.

"Por lo tanto, a la hora de difundir la información en la sociedad de la digitalización, hay que tener muy en cuenta el también diferente papel que ostenta el usuario. Ya no es el consumidor pasivo frente al bombardeo de los distintos emisores: El consumidor pierde su carácter de agente pasivo para ser ascendido a la categoría de 'coproductor' o 'prosumidor', significativo matrimonio semántico” (Mattelart 2000: 409).

Efectivamente, el usuario del Facebook crea - recrea y expone en texto e imagen el acontecer importante de un momento significativo. El objetivo, obviamente, es informar en el marco de una agenda personal, "la noticia de su vida", para beneplácito de su público o seguidores a los que comúnmente les da la categoría de "amigos". En el espacio virtual los usuarios exponen situaciones personales, como si estuviéramos en grandes tiendas comerciales, todo se encuentra en vitrina. Los usuarios exponen su privacidad, la coloca a la vista, modifica enunciados e incluso los puede eliminar o descartar las opiniones de otros en una dinámica de actualización rápida y eficiente. 
"Las nuevas tecnologías han supuesto una trasformación radical en la función que desempeñaba el público. Con la acumulación, procesamiento y recuperación automatizada de datos se produce una alteración decisiva en la mediación. El receptor de la comunicación tiende a convertirse en usuario en el sentido de que participa en el proceso de selección -de interacción- para recuperar la información previamente acumulada” (Moragas, 1993: 18).

En esta reflexión, muchos comunicadores, estudiosos e investigadores centran su interés en las redes sociales, sus discursos y procesos de consumo. Pero, inquieta de alguna manera, cómo abordar de manera coherente un estudio sobre el particular, considerando planteamientos teóricos o paradigmas que expliquen o que traten de explicar cómo los usuarios calificados como productores y consumidores intervienen en procesos de comunicación mediatizados por un espacio virtual en el Facebook. Bajo este lineamiento y para efectos de llevar a cabo de manera práctica un estudio particular, se explicará de qué manera los usuarios del Facebook usan las herramientas de la plataforma para crear discursos, tomando un caso específico, en el que un usuario cualquiera produce un enunciado que, de alguna u otra manera, genera polémica.

\section{Planteamiento teórico}

Con las nuevas tecnologías en los procesos de comunicación algunos teóricos se encuentran bajo la perspectiva de dos planteamientos. Según Maribel Velarde Tovar (2006, pág. 1) señala que "en Latinoamérica las ciencias de la comunicación han transitado por: los procesos funcionalistas-estructuralistas (dictado por las hegemonías europeas y norteamericanas) y la postura beligerante y de denuncia, inspirados en la semiótica, el imperialismo cultural y la dependencia”.

Es difícil determinar qué tendencia optar, pero al dar un formalismo académico al presente trabajo, se consideran adecuados los procesos funcionalistas-estructuralistas en el marco del discurso mediado en el Facebook. "La convergencia de informática, telecomunicaciones y medios audiovisuales digitales han propiciado cambios profundos en los procesos de organización, producción y análisis de la sociedad 
contemporánea, en medio de los cuales se insertan los medios de comunicación, en donde los electrónicos siguen conservando su primacía. Pero, actualmente los receptores han abandonado su pasiva condición de consumidores culturales y hoy por hoy gracias a los formatos digitales, las formas de interrelación han cambiado dando paso a la conectividad e interactividad" (Velarde Tovar, 2006: 3).

En el marco de las investigaciones en el campo Funcionalista tenemos aquel referido por la pregunta ¿qué hace la gente con los medios de comunicación?, es decir, la de Usos y Gratificaciones. Paradigma que en la década de los ochenta consideró que "la recepción y el individuoconsumidor ocupan un lugar central en la concepción neoliberal de la sociedad. No se trata de cualquier consumidor llamado soberano en sus selecciones, en un mercado llamado libre." (Mattelart, 1997: 103).

Ya Elihu Katz señaló en 1959 que "ni siquiera el mensaje del más potente de los media puede normalmente influenciar a un individuo que no se sirva de él en el contexto socio-psicológico en el que vive" (Wolfe, Mauro, 1987: 32). La teoría de Usos y Gratificaciones sugiere que las personas usan los medios de comunicación, o en todo caso sus contenidos, para satisfacer necesidades (informativas, afectivas, de integración y de entretenimiento) basadas en experiencias personales.

Con esto no se quiere decir que las personas obtienen lo que buscan en los medios. Por el contrario, cada miembro de la audiencia elige de acuerdo a sus objetivos y necesidades personales. Esto supone que la audiencia aislada y con necesidades diversas, da por sentado que usa los medios con diferentes objetivos e intereses y también de forma distinta y selectiva. El planteamiento funcionalista no solo se funda en las gratificaciones que se pudiera conseguir de los contenidos mediáticos, sino del tipo de exposición al medio y del contexto social del consumo gratificante.

De allí que se considera el concepto de "Audiencias Activas", es decir "el patrón de uso de medios se debe a una motivación psicológica, a una necesidad, y dependiendo de esa necesidad los individuos escogen ciertos medios y contenidos" (Fernández, Carlos y Galguera, Laura 2009: 105). Sin embargo, al respecto James Lull, profesor emérito en Estudios de Comunicación de la Universidad de San José (California), 
considera que posiciones fundadas en aspectos psicológicos no se pueden tomar como generalizadoras sobre los procesos comunicacionales.

"Como las teorías psicológicas, las perspectivas de los usos y gratificaciones se sustenta en gran medida en conceptos cognitivos tales como las necesidades, los motivos y las gratificaciones y no indagada lo suficiente las cuestiones estructurales más generales" (Lull, James. 1995: 131). Según el autor los investigadores del campo de la Psicología han tratado de explicar la teoría de Usos y Gratificaciones y no han llegado a plantear una adecuada teoría cognitiva y reconoce que los estudios pueden brindar explicaciones parciales de la actividad de la audiencia, considerando que se estudia de cerca o individualmente a la persona, idea que no la descarta.

De allí que se desarrolla aspectos de "la estrecha relación que entabla la gente con los medios. "Me concentraré directamente en ciertos conceptos concretos de los usos y gratificaciones, tales como la necesidades y los motivos, y agregaré al análisis otras ideas clave como los métodos y la imaginación" (Lull, James 1995: 132). Para el desarrollo aplicativo del presente trabajo se tendrán en cuenta los conceptos que formula Lull, pues el disfrute de los medios es un hecho individual bajo un contexto social y que incluye las funciones cumplidas por los medios para el individuo, obviamente, en el tema de las gratificaciones que tiende a "sobrevalorar la libertad del público" en la selección de los medios y de sus discursos.

\section{Analizando el caso}

El discurso, según Óscar Quezada Macchiavelo no es un mensaje. "Mensaje es la categoría que, con frecuencia, se emplea desde fuera de la semiótica para hablar de esta misma realidad. Pero resulta que este término proveniente de una teorización general, por lo difundida, sobre la comunicación; así, en singular, resulta pobre, extremadamente reductor, por decir lo menos, para una imaginación que proyecta similar la búsqueda humana de sentido; es decir, la producción de sentido entre-tejido, articulado, estructurado. Antes que nada, texto es entretejido de mensajes (nivel concreto) y de sistemas de significación 
(nivel abstracto). De discursos y de gramáticas. Concretamente, todo texto actualiza mensajes particulares que dis-curren entre dos polos (destinador/destinatario): estos mensajes particulares constituyen, pues, lo que se puede llamar discurso". (Quezada, 1991:33).

Se ha iniciado este punto con una aclaración propia de los comunicadores que se preocupan por los procesos de significación de los discursos, con el objetivo de darle al trabajo el carácter estructuralista que anteriormente habíamos mencionados. Detallaremos las características del discurso virtual y además, pues en algún momento, no se podrá evitar el sentido de los enunciados expresados por los usuarios, es decir, expresiones afectivas positivas y negativas ante el estímulo-enunciado.

En el caso propuesto, se trata del Facebook de una persona que posee mil 567 "amigos" que observan todo lo que el titular considera pertinente hacerlo público. El discurso materia de análisis fue un enunciado que dice: "Una agrupación política me ha propuesto ser candidata al Congreso de la República en el 2016. ¿Opiniones?”. La reacción fue inmediata: tres minutos de demora en la respuesta. Finalmente, se tuvo 123 "me gusta" (likes), es decir, se refiere al número de personas que observaron la oración; y 92 comentarios, es decir, personas que leyeron el enunciado y reaccionaron al redactar sus opiniones y pareceres sobre el particular. El enunciado fue publicado el 17 de noviembre y se tuvo comentarios hasta el 01 de diciembre, después de esa fecha se perdió la noticiabilidad "personal" del usuario.

Hay que destacar la rapidez en la reacción por parte de los receptores, y la facilidad que da el sistema en contestar a una pregunta, como una especie de consejería virtual, lo que hace que los "amigos" opinen y produzcan una respuesta discursiva en el marco de un proceso de comunicación de estímulo - respuesta y respuesta - estímulo. La inmediatez es un factor importante, facilita a los receptores responder desde sus sofisticados celulares; tablets, notebooks; y otros equipos. E incluso la respuesta se produce en cualquier espacio social en el que se encuentren los destinatarios-destinados: la casa, el trabajo, el centro de estudios, la calle y otros.

En tal sentido, tomando los lineamientos de James Lull sobre necesidades-motivos y métodos-imaginación, se iniciará con las reflexiones sobre el uso que dan las audiencias activas a los medios 
para obtener satisfacciones. Además, partamos de la "necesidad" del titular de la cuenta al anunciar y pedir opinión a sus "amigos" sobre la propuesta de un partido político en un contexto social en el que se observa denuncias a políticos como el caso Orellana y Belaúnde, entre otros; y que incluso se tiene muchos comentarios negativos sobre las personas de nuestra política nacional. Se considera que el contexto en el que convergen los enunciados en cualquier medio de comunicación es importante.

Sobre las necesidades, Lull cita a varios investigadores sobre el término desde planteamientos biológicos hasta aspectos culturales de los mismos. "Las necesidades reciben la influencia de la cultura, no solo en cuanto a cómo se determinan, sino también en lo referente al modo de satisfacerlas" (Lull, 1995: 134). ¿Qué necesidades tiene el titular de la cuenta del Facebook para redactar un enunciado de esa envergadura? En principio, se puede determinar que existe una necesidad básica de informarse, de alguna u otra manera, o de conocer qué piensan sus "amigos" seguidores de su vida sobre el particular: Si están de acuerdo o no.

$\mathrm{Al}$ respecto, se pueden citar opiniones a favor como: "usted tiene pantalones"; "Daleeeiii; "Debería intentarlo"; "Yo también votaría por usted"; "Mi voto más que fijo"; "Usted gana”; "Acepta”; Do it ¡!!; entre otros. Son los enunciados de respuesta más recurrentes y que expresan el apoyo al productor que inició el proceso de comunicación. Sin embargo, existe la otra postura: la negativa, la que sugiere que no es "buena idea" incursionar en la política. De los 92 comentarios siete de ellos fueron en esa vertiente. De allí que podemos citar: "No, como congresista no. Como cuadro técnico mejor"; "No le conviene"; "Honestamente no se lo deseo ni a mi peor enemigo"; "meterte en la política te puede quemar"; y "mmm la verdad, sería mucho mejor como alcaldesa que congresista jejeje".

"La gente se relaciona intencionalmente con el mundo social para satisfacer sus necesidades. Estas acciones sociales exigen una energía y una dirección básica, que los psicólogos generalmente atribuyen a motivos" (Lull, 1995: 137). ¿Qué motivó al titular de la cuenta de Facebook a colocar dicho enunciado? ¿Solo quiso saber las opiniones? ¿Quiso sentirse seguro con las opiniones? Con relación a la segunda pregunta asumimos que sí se cumplió con esa necesidad básica de 
informarse y conocer los comentarios. Sin embargo, el titular de la cuenta no solo obtuvo opiniones sino también expresiones que reflejan la imagen que tienen sus "amigos" sobre él, satisfaciéndose aún más necesidades afectivas relacionadas con su autoestima y reconocimiento de cualidades por parte de los otros.

Aquí se pueden mencionar frases como: "Usted tiene pantalones"; "Sería una luz en tanta oscuridad, su carácter ayudará mucho en combatir tanta corrupción de los supuestamente llevan la batuta del país"; "Vaya.... Por lo menos alguien hará el cambio en tanta corrupción", "Sí! Alguien decente hace falta hace rato por esos lares!!!”; "usted califica”. "Si vas a ser tan exigente como congresista como lo eres como directora, tienes mi voto asegurado...."; "mmm lista, honesta, inteligente..... fastidiosa jejeje, con el respeto que se merece"; entre otros.

La necesidad-motivos son conceptualizaciones inseparables. Debemos cuestionarnos que lo motivó al productor construir dicho discurso. Es allí el punto en el que los estudios psicológicos darían explicaciones puntuales. Sin embargo, bajo el paradigma de los Usos y Gratificaciones se puede señalar que el productor se vio motivado por informarse sobre qué piensan sus amistades sobre la propuesta, es decir, la motivación a necesidades cognitivas: Información sobre el entorno; consejo sobre decisiones práctica; Satisfacción de la curiosidad; autoaprendizaje y seguridad a través del conocimiento.

Con relación al Método, Lull sostiene que es un medio motivado de satisfacer una necesidad y que se compone de un plan cognitivo y de una actividad. Además, son llevados a cabo por actores sociales, con el fin de alcanzar objetivos puntuales que satisfaga sus necesidades. "Cuando alguien utiliza un medio de comunicación masiva con tales propósitos, decimos que hace un uso del medio. El uso es parte del método" (Lull, 1995: 142).

Es evidente que el usuario productor del enunciado usó el medio y obtuvo resultados gratificantes, es lo que Lull denomina como "alternativa funcional". El uso del Facebook, para el titular, le resultó más dinámico, pues consiguió comentarios de manera rápida y puntual; y en mayor número. Cosa, que no hubiera podido obtener en una reunión social con amigos y en relación cara a cara, sin instrumentos mediáticos de por medio. 
Además, el dominio del lenguaje propio de las redes sociales, especialmente del Facebook, hace que el productor codifique o construya el discurso, que en este caso, fue textual, pero pudo incluirle material gráfico como fotografías o dibujos y otros materiales. Un destinador, en cuanto a dominio de las redes sociales, se encuentra en igual nivel de dominio del lenguaje digital de sus amistades.

\section{A manera de conclusión}

Todo apunta a pensar en la reflexión final que las audiencias activas hacen uso de los medios de acuerdo a sus necesidades de reconocimiento por grupos sociales determinados y por sus relaciones; lo que origina su participación activa con comentarios, como es el caso. El Facebook es un mundo virtual de convivencia y que los usuarios de cada una de las aplicaciones y tienen perfecto conocimiento de sus dominios e instrumentos. Llevar a cabo un estudio en amplias audiencias activas es imposible. Sin embargo, es importante reconocer el uso de los medios ante estímulos importantes y resaltantes.

Para ello se puede realizar estudios de las audiencias desde una perspectiva que solo lineamientos psicológicos pudieran responder a las necesidades y motivaciones que tienen las personas en el uso de los medios de comunicación, especialmente, en las redes sociales. La utilización de instrumentos estadísticos podrían, de alguna manera, dar a conocer el uso que le dan los usuarios a los medios de comunicación. Estamos hablando de diseńos descriptivos cuantitativos aplicados a amplias audiencias. También los estudios de los audiencias, si solo queremos conocer las necesidades y motivaciones de un solo grupo de personas específicos, podemos realizarlo a través de los focus group y conocer mediante la técnica de mapeamiento de respuestas las constantes que puedan presentarse en las opiniones de las personas participantes. Obviamente este último recurso corresponde a los diseños descriptivos cualitativos.

En lo que respecta al discurso se puede realizar el análisis de contenido ya propuesto entendido como la interpretación de significados en distintas áreas de lo simbólico, particularmente en interpretaciones de 
textos. Es decir la interpretación puede darse desde lo estrictamente manifiesto, lo explícito o expreso; en otras pretenden desentrañar lo implícito, lo oculto o latente en un discurso como el presentado en las redes sociales, especialmente, en el discurso propuesto en el que se puede apreciar sentimientos, opiniones a favor y en contra.

\section{$\underline{\text { Referencias }}$}

Figueroa, Romeo. (2013). Introducción a las Teorías de la Comunicación. Pearson Educación de México S.A.

Fernandez Collado, Carlos y Galguera García, Laura. (2009). Teorías de la Comunicación. Mc Graw Hill.

Lull, James (1995). Medios, Comunicacióny Cultura. A Global Approach. New York. Columbia University Press.

Lopez Lita, Rafael y Fernandez Beltran Francisco. (2005) La comunicación local por Internet. Publicaciones de la Universitat Jaume I. Moragas, Miquel. (1993). Teorías de la comunicación: investigación sobre medios en América y Europa. Barcelona: G. Pili.

Mattelart, Armand. (1995). La invención de la comunicación., notas y aportaciones bibliográficas de Gilles Multigner. Barcelona: Bosch.

Mattelart, Armand. (2003). Historia de la Teorías de la Comunicación. Edición Paidos Ibérica S. A.

Velarde Tovar, Maribel. (2006). Los Retos de las Teorias de la Comunicación en el siglo XXI. Disponible en: http://www.revista.unam.mx/vol.7/ num6/art51/jun art51.pdf

Wolfe, Mauro. (1985) La investigación de la comunicación de masas. Edición Paidos. 